\title{
Drought Adaptation in Fuchsia magellanica and Its Effect on Freezing Tolerance
}

\author{
Majken Pagter ${ }^{1}$ and Karen K. Petersen \\ Department of Horticulture, Faculty of Agricultural Sciences, University of Aarhus, Kirstinebjergvej \\ 10, DK-5792 Aarslev, Denmark
}

Fulai Liu and Christian R. Jensen

Department of Agricultural Sciences, Faculty of Life Sciences, University of Copenhagen, Hoejbakkegaard Allé 9, DK-2630 Taastrup, Denmark

\begin{abstract}
AdDitional INDEX words. osmotic adjustment, abscisic acid, electrolyte leakage, proline, carbohydrates, cold resistance, water stress

Abstract. Fuchsia (Fuchsia L.) is a popular woody ornamental, but it is very susceptible to frost injury during winter. As drought stress may be used to enhance freezing tolerance in woody plants, the effects of different types of water deficit on growth, selected physiological traits, and freezing tolerance were examined in Fuchsia magellanica Lam. 'Riccartonii'. Drought responses were investigated after 6 weeks of pretreatment, where individual plants grown in a greenhouse under conditions of unrestricted water supply were compared with plants subjected to cyclic or continuous water deficit. After an additional 4 weeks of treatment at short day $(10 \mathrm{~h})$ and low temperature $\left(8^{\circ} \mathrm{C}\right.$ day $/ 4{ }^{\circ} \mathrm{C}$ night), freezing tolerance was examined. Both continuous and cyclic water deficit plants reduced water loss by reducing aboveground biomass and by efficient stomatal regulation. Continuous water deficit plants tended to adjust osmotically, while cyclic water deficit induced significantly higher xylem sap abscisic acid [(ABA $)_{x y l e m]}$ and leaf proline concentrations and a lower leaf water potential $\left(\psi_{1}\right)$ than continuous water deficit, indicating that $F$. magellanica responds differently to continuous water deficit and to fast drying associated with stress phases of cyclic water deficit. The root water potential $\left(\psi_{r}\right)$ and $(A B A)_{x y l e m}$ were negatively linearly correlated, implying that increasing water deficiency stimulated formation of $\mathrm{ABA}$ in the roots. An inverse, curvilinear relation between (ABA) $)_{x y l e m}$ and stomatal conductance $\left(g_{s}\right)$ indicated that root-originated ABA might control $g_{s}$ during mild water deficits. Neither cold-acclimating conditions alone nor combined with water deficit increased stem freezing tolerance, indicating that $F$. magellanica lacks cold-acclimation ability under the inductive conditions used in this study.
\end{abstract}

Fuchsia magellanica is a prevalent woody ornamental in Denmark and in many other countries in the temperate zone. It is regarded as one of the hardiest outdoor Fuchsia species, but aboveground parts can be frost-injured or have dieback to the ground in winter and the new growth in spring, even on mature plants, is frost-tender. Plants that show dieback to the ground in winter are occasionally able to produce new shoots from belowground parts in spring, and frost-injured plants usually recover well but do not start growing quickly until late spring and flowering occurs late summer. To avoid frost injury and thereby substantial economic losses, Danish producers of fuchsia usually store $F$. magellanica at about $-1{ }^{\circ} \mathrm{C}$ during winter. Increased freezing resistance would make it possible to over-winter $F$. magellanica outdoors and still obtain a highquality product, and it would enhance the marketing potential of $F$. magellanica as a garden shrub. F. magellanica is native to the southern Andes (Berry et al., 2004), which have a temperate climate, with mean monthly temperatures between $\approx 2.4$ and $-2.8^{\circ} \mathrm{C}$ in the coolest month (Wardle et al., 2001). However, according to Villalba et al. (2003), who reported that the mean temperature of the coolest month ranges between 0 and $4{ }^{\circ} \mathrm{C}$, absolute minimum temperatures may be lower than $-25^{\circ} \mathrm{C}$.

Strategies allowing plants to tolerate subzero temperatures are mainly of two types: freezing avoidance and freezing

Received for publication 21 May 2007. Accepted for publication 18 Sept. 2007. We thank Ian Henson and Martin Jensen for helpful comments on the manuscript.

${ }^{1}$ Corresponding author. E-mail: majken.pagter@agrsci.dk. tolerance. Tissues displaying freezing avoidance escape frost injury by lowering the freezing point within the cells with antifreeze substances like sugars, alcohols, and proteins. Accumulation of antifreeze substances only lowers the freezing point by a few degrees and can be regarded as a shallow supercooling strategy that will not succeed in environments where prolonged, deep, subfreezing temperatures exist. Freezing avoidance is a resistance mechanism mainly used by freezing-sensitive plants. However, some freezing-sensitive plants cannot be frost-acclimated at all and are injured at very mild freezing temperatures. Freezing-tolerant plants survive freezing by letting ice form extracellularly, which is a process associated with cellular dehydration (Guy, 2003; Sakai and Larcher, 1987; Wisniewski et al., 2003). In many woody plant species, cold acclimation, or development of freezing tolerance, is regulated by the shortening of photoperiod and by declining temperature (Weiser, 1970; Welling et al., 2002). However, other triggers than low temperature and short photoperiod are known to influence development of freezing tolerance. Drought stress-induced increase in freezing tolerance has been reported for some woody plants from the Northern Hemisphere (Anisko and Lindstrom, 1996; Li et al., 2002; Rinne et al., 1998). The common denominator of drought and environmental triggers of cold acclimation is the promotion of cellular dehydration, and water deficit induces several responses similar to those changes observed in cold-acclimating woody plants. Among these are reduced growth (Li et al., 2005), reduced tissue water content (Anisko and Lindstrom, 1996), osmotic adjustment, defined as an increase in osmotic 
pressure of cell sap resulting from more organic and inorganic solute molecules per cell (Amundson et al., 1993; Munns, 1988; Rinne et al., 1998) and increased endogenous levels of ABA (Aasamaa et al., 2002; Guak and Fuchigami, 2001; Gusta et al., 2005; Welling et al., 1997).

Osmotic adjustment is associated with a lowering of the osmotic potential $\left(\psi_{\mathrm{S}}\right)$ inside the cell. Under cold conditions, this is believed to lower the freezing point of the cell, reducing the probability of ice crystal formation. Additionally accumulated organic molecules may protect cell membranes and vital macromolecules by maintaining their structural stability (Gusta et al., 2004; Li et al., 2004). Organic compounds often accumulating in cold-stressed woody plants include soluble carbohydrates, various proteins including dehydrins and other late-embryogenesis-abundant (LEA) proteins, glycine betaine, and proline (Arora et al., 1992; Lennartsson and Ögren, 2002; Rinne et al., 1998; Xin and Browse, 2000).

ABA, a well-known stress-inducible plant hormone, is suggested to mediate plant responses triggering cold acclimation and drought adaptation. ABA levels have been reported to increase in tissues of both herbaceous and woody plants subjected to drought or cold stresses (Li et al., 2002; Skriver and Mundy, 1990), and application of ABA can induce increasing freezing tolerance and drought tolerance (Guak and Fuchigami, 2001; Shinozaki and Yamaguchi-Shinozaki, 1996). There is a wealth of evidence demonstrating the involvement of ABA in root water availability perception, root-to-shoot communication regulating stomatal aperture and leaf growth, and altered gene expression in water deficit plants (Chaves et al., 2003; Davies et al., 2005; Loewenstein and Pallardy, 2002). In cold-acclimating plants, ABA is believed to be involved in photoperiod or temperature perception, water status alterations and osmoregulation, and in induction of coldresponsive genes (Rinne et al., 1998; Shinozaki and Yamaguchi-Shinozaki, 1996).

Due to the similarities between plant responses to water deficit and to low temperatures, we hypothesized that freezing tolerance of $F$. magellanica may be increased by exposure to water deficit before cold. To our knowledge, no studies have been conducted investigating either effects of reduced water availability on the physiology of $F$. magellanica or its freezing tolerance. The objectives of the present study were to 1) determine effects of different applications of water deficit on growth and selected physiological traits in F. magellanica plants grown in controlled conditions and 2) determine if these effects were associated with changes in freezing tolerance. This was done by evaluating effects of continuous water deficit and cyclic water deficit on $F$. magellanica plants followed by short day and low temperature acclimation under controlled conditions. Freezing tolerance was determined in nonacclimated, fully watered plants and in acclimated plants either fully watered or subjected to continuous or cyclic water deficit.

\section{Materials and Methods}

Plant material and experimental treatments. In May 2005, cuttings of $F$. magellanica were stuck in plugs in sphagnum peat and covered by plastic under greenhouse conditions at $22{ }^{\circ} \mathrm{C}$. After 5 weeks, rooted plants were potted in sphagnum peat in $0.67-\mathrm{L}$ pots. The potted plants were grown under natural light conditions (17-h photoperiod) at $21^{\circ} \mathrm{C}$ day and night with venting at $25^{\circ} \mathrm{C}$. When radiation reached 900
$\mathrm{W} \cdot \mathrm{m}^{-2}$ [equivalent to a photosynthetic photon flux density $(P P F)$ of $\left.\approx 1700 \mu \mathrm{mol} \cdot \mathrm{m}^{-2} \cdot \mathrm{s}^{-1}\right]$, insulating curtains were drawn. During production, plants were ebb- and flood-irrigated daily with a standard nutrient solution containing (in $\mathrm{mm}$ ): $11.7 \mathrm{~N}, 0.8$ $\mathrm{P}, 5.4 \mathrm{~K}, 3.5 \mathrm{Ca}, 0.8 \mathrm{Mg}$, and $1.4 \mathrm{SO}_{4}$, at electrical conductivity (EC) 1.7 and $\mathrm{pH}$ 5.8. Micronutrients were added, making up $0.1 \%$ of the nutrient solution. The plants were cut back twice during production.

At onset of the experiment, 90 plants of uniform size were selected. Of these plants, 10 were randomly chosen and the pots were weighed daily to determine mean water consumption per plant. The soil-water potential $(\psi)$ was determined by tensiometers (E-sensors, 0-1000 hPa; Tensio-Technik, Geisenheim, Germany) randomly positioned in three pots per treatment connected to a DT 505 data logger (Datataker Pty Ltd, Rowville, VIC, Australia). Below $-50 \mathrm{kPa}$, the tensiometers were no longer reliable due to loss of contact between tensiometer and growing media, and treatments were based on gravimetric water loss. The remaining 80 plants were randomly arranged into three groups. Based on daily mean water consumption, control plants $(n=40)$ were top-watered daily with a volume of nutrient solution equal to $100 \%$ of evapotranspiration. The two treatment groups $(n=20)$ included two types of water availability treatments: continuous water deficit and cyclic water deficit.

At onset of the experiment, irrigation was withheld from continuous and cyclic water deficit plants until visible turgor loss. Thereafter, continuous water deficit plants were given an amount of nutrient solution equal to $40 \%$ of mean daily water consumption throughout the rest of the experimental period. The cyclic water deficit treatment was a repeating nonlethal cyclic water deficit treatment alternating between stress phases, where watering was withheld, and recovery phases where the plants received the same amount of water and nutrient solution as control plants for $5 \mathrm{~d}$. Although water treatments were based on mean water consumption, at regular intervals all pots were weighed and weight adjustments were made on an individualpot basis. In addition, three pots per treatment were weighed daily. Changes of daily pot weight throughout the experiment are shown in Fig. 1 . In total control plants received $\approx 3.8 \mathrm{~L}$ of water per plant during the experiment, while continuous and cyclic water deficit plants received $\approx 1.4$ and $\approx 1.8 \mathrm{~L}$ per plant, respectively. Pots were rotated daily to ensure a random distribution of growth conditions in the greenhouse.

After $\approx 6$ weeks of treatment, plant-water relations were determined, five plants per treatment were harvested, and samples were collected for further analyses. During measurements, the cyclic water deficit plants were in a stress phase. After harvest, the remaining water deficit plants and half of the rest of the control plants were cold-acclimated in a climate chamber at $8{ }^{\circ} \mathrm{C}$ day $/ 4{ }^{\circ} \mathrm{C}$ night temperature (LT), 60-100 $\mu \mathrm{mol} \cdot \mathrm{m}^{-2} \cdot \mathrm{s}^{-1}$, and a daily photoperiod of $10 \mathrm{~h}$ (SD). Water deficit regimes were continued in the climate chamber, and hence the treatments applied in the climate chamber were control $+\mathrm{SD}+\mathrm{LT}$, constant water deficit $+\mathrm{SD}+\mathrm{LT}$, and cyclic water deficit $+\mathrm{SD}+\mathrm{LT}$. Another half of the control plants stayed in the greenhouse under a long day/warm temperature regime and served as nonacclimated control plants.

Stomatal Conductance and Plant-water Relations MEASUREMENTS. Stomatal conductance to water vapor $\left(g_{\mathrm{s}}\right)$ of one of the third youngest fully expanded leaves was measured after $\approx 6$ weeks of treatment with a CIRAS-2 IR gas analyzer 


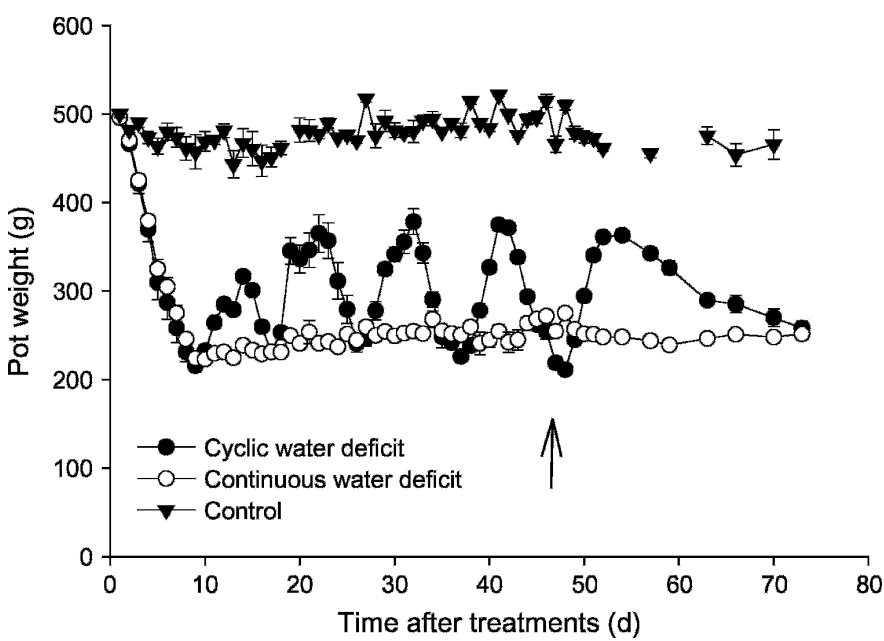

Fig. 1. Mean pot weight of Fuchsia magellanica plantlets during 6 weeks of pretreatment followed by 4 weeks of short-day and low-temperature $(10 \mathrm{~h}$; $8{ }^{\circ} \mathrm{C}$ day $/ 4^{\circ} \mathrm{C}$ night) acclimation. Plants were well-watered or subjected to continuous or cyclic water deficit during the entire period (means $\pm \mathrm{SE}, n=3$ ). Arrow denotes when short day and low temperature acclimation was initiated.

(IRGA) equipped with a PLC6 Leaf Cuvette (PP Systems, Hertfordshire, U.K.). The humidity of the air stream was at $80 \%$ relative humidity $(\mathrm{RH})$, and light was supplied from a lightemitting diode (LED) light source at a PPF of 1000 $\mu \mathrm{mol} \cdot \mathrm{m}^{-2} \cdot \mathrm{s}^{-1}$. Measurements were made between 1100 and $1400 \mathrm{HR}$, and readings were logged every $30 \mathrm{~s}$ until stable values of $g_{\mathrm{s}}$ were reached.

Midday leaf water potential $\left(\psi_{1}\right)$ was measured with a pressure chamber (SKPM 1400; Skye Instruments Ltd, Llandrindod Wells, U.K.). Because of the short petioles in $F$. magellanica, it was impossible to seal a single leaf in the vessel. Consequently, a stem further up the plant with two to four pairs of leaves was sealed, and $\psi_{1}$ was then recorded. Leaf osmotic potential $\left(\psi_{\mathrm{s}}\right)$ was determined on the same tissues after determination of $\psi_{1}$. The samples were wrapped tightly in aluminum foil, frozen in liquid nitrogen, and stored at $-80^{\circ} \mathrm{C}$. After thawing, samples were placed in silicone tubes and sap was expressed by squeezing the tubes in a vice. The $\psi_{\mathrm{s}}$ of the sap was measured at $20{ }^{\circ} \mathrm{C}$ by psychrometers (C-52 sample chambers; Wescor, Logan, UT). Values of $\psi_{\mathrm{s}}$ were averages of two measurements from each sample. Leaf turgor pressure $\left(\psi_{\mathrm{p}}\right)$ was calculated as the difference between $\psi_{1}$ and $\psi_{\mathrm{s}}$.

Tissue analysis AND Plant BIOMass. At harvest, $1-2 \mathrm{~g}$ fresh weight $(\mathrm{FW})$ of the fourth youngest fully expanded leaves of each plant were harvested and frozen in liquid nitrogen for determination of carbohydrates. Concentrations of hexose (glucose + fructose) and sucrose were determined by highperformance liquid chromatography (HPLC) (model 1047A; Hewlett Packard, Waldbronn, Germany) as described by Liu et al. (2004). Starch was determined in the remaining pellets after extraction of soluble sugars. The pellets were dried in a vacuum centrifuge, and the starch was gelatinized by boiling for $1 \mathrm{~h}$ with a thermostable amylase (Termamyl; Novo Nordisk, Glostrup, Denmark) in a $5 \mathrm{~mm}$ sodium dihydrogen phosphate buffer ( $\mathrm{pH}$ 6.0). After centrifugation, the gelatinized starch in the supernatant was further hydrolyzed with amyloglucosidase (Roche Diagnostics, Basel, Switzerland) in $50 \mathrm{~mm}$ sodium acetate buffer and $15 \mathrm{~mm}$ magnesium chloride $(\mathrm{pH} 4.6)$ at $55^{\circ} \mathrm{C}$ for $1 \mathrm{~h}$. The extracts were purified by anion-exchange Sephadex
QAE-A-25 (Pharmacia Biotech, Uppsala, Sweden) chromatography. The columns (1.0-mL volume) were pre-equilibrated with $0.5 \mathrm{~mL}$ of sodium formate and washed with $50 \mathrm{~mL}$ of 0.05 M sodium formate before sample application. The eluates were evaporated to dryness and redissolved in $0.5 \mathrm{~mL}$ of water, and the glucose concentration was analyzed on HPLC.

At the same time, leaves were sampled for quantification of proline concentrations. Between 250 and $500 \mathrm{mg} \mathrm{FW}$ of the second youngest fully expanded leaves of each plant was excised and frozen in liquid nitrogen. The samples were later analyzed using the acid-ninhydrin procedure described by Tamayo and Bonjoch (2001). In short, proline was determined colorimetrically by absorbance of the proline-ninhydrin product at $520 \mathrm{~nm}$ in a spectrophotometer using toluene as a solvent.

Leaf biomass was determined by recording the number and FW and dry weight (DW) of green, living leaves on five plants per treatment. Immediately after excision, the area of a subsample of leaves was determined using an area meter (LI-3000; Lambda Instruments Corp., Lincoln, NE). The area/FW ratios of the subsamples were used to calculate total leaf area of each plant. Average leaf size was determined by dividing total leaf area with total number of leaves. Specific leaf area (SLA) was calculated as total leaf area (square centimeters) per total DW of leaf biomass (grams).

COLLECTION OF XYLEM SAP AND DETERMINATION OF XYLEM SAP (ABA). Potted plants were transferred to a Scholander-type pressure chamber and decapitated $\approx 5 \mathrm{~cm}$ above the soil surface. With the stem stump protruding outside the chamber, pressure was applied until the root water potential $\left(\psi_{\mathrm{r}}\right)$ was equalized. After determination of $\psi_{\mathrm{r}}$, the cut surface was cleaned with pure water and dried with blotting paper, and the root system was gradually pressurized until the pressure equaled $\psi_{1}$. Before pressurizing the root system to $\psi_{1}$, a piece of silicon tube was placed on the protruding stem, leading exuded xylem sap into an Eppendorf vial wrapped with aluminum foil. Xylem sap was collected for 30-45 min and thereafter stored at $-80{ }^{\circ} \mathrm{C}$ until further analysis. The ABA concentration in xylem sap was determined without purification by an ELISA enzymelinked immunosorbent assay (ELISA) using a monoclonal antibody for ABA (AFRC MAC 252) according to Asch et al. (2001).

Determination OF FREEZING TOLERANCE. Freezing tolerance of stems was determined from four replicate samples per treatment after 6 weeks of treatment in the greenhouse followed by 4 weeks of treatment under cold-acclimating conditions. Freezing tolerance was determined at 10 test temperatures, ranging from 20 to $-20{ }^{\circ} \mathrm{C}$, by measuring the extent of freezing injury using the ion-leakage method. Four 2-cm-long pieces of internodal stem tissue were rinsed under cold running tap water for $30 \mathrm{~s}$ and then under running demineralized water for $15 \mathrm{~s}$. After they were rinsed, the samples were placed in $70-\mathrm{mL}$ test tubes and incubated in a controlled freezer. Few drops of demineralized water were added to each sample to initiate ice formation. The freezer cooled at a maximum rate of $5^{\circ} \mathrm{C}$ per hour to $0{ }^{\circ} \mathrm{C}$ and subsequently at $2{ }^{\circ} \mathrm{C}$ per hour until the selected temperature was reached. The selected temperature was maintained for $2 \mathrm{~h}$, after which time the samples were withdrawn and thawed at $4{ }^{\circ} \mathrm{C}$. Ions were extracted with $35 \mathrm{~mL}$ of demineralized water for $20 \mathrm{~h}$ at room temperature and the EC was measured $\left(\mathrm{EC}_{\text {frozen }}\right)$ using an ION570 ISE meter with temperature-corrected display (Radiometer, Copenhagen, Denmark). After determination of the EC, the samples were autoclaved for 
$1 \mathrm{~h}$ to allow maximum leakage of ions. After autoclaving, the samples were allowed to cool to room temperature and the EC was measured again $\left(\mathrm{EC}_{\text {autoclave }}\right)$. The $\mathrm{EC}$ of demineralized water $\left(\mathrm{EC}_{\mathrm{water}}\right)$ was measured to give the zero level of $\mathrm{EC}$. Relative electrolyte leakage (REL) was calculated as $\left(\mathrm{EC}_{\text {frozen }}\right.$ $\left.-\mathrm{EC}_{\mathrm{water}}\right) \times 100 /\left(\mathrm{EC}_{\text {autoclave }}-\mathrm{EC}_{\text {water }}\right)$.

Even when aboveground parts of $F$. magellanica show dieback to the ground in winter, plants are occasionally able to produce new shoots from below ground parts in spring. Hence, to investigate whether $F$. magellanica root and stem freezing resistance varies or whether the apparent greater root freezing resistance is due to insulation by the soil, root freezing tolerance was also determined. Freezing tolerance was determined in February in roots of untreated pot-grown plants kept outdoors, shielded by a net, under natural cold-acclimating conditions. Due to the rather late date of investigation and thus risk of deacclimation, and as a result of an error in the programmable freezer which made it stop freezing when it reached $-8{ }^{\circ} \mathrm{C}$, root freezing tolerance was also determined in untreated 2-year-old commercially produced plants cold-acclimated outdoors during autumn and stored at $-1{ }^{\circ} \mathrm{C}$ during winter. Peat was carefully removed from the roots by rinsing for 1 min under cold, running tap water. Subsequently remaining peat residues etc. were removed by hand, and roots were diprinsed in three beakers containing $0.2 \mathrm{~L}$ of demineralized water. Roots of plants kept outdoors were pooled from four plants per replicate, and samples of $100-300 \mathrm{mg}$ consisting of 1-3 root pieces were prepared from roots $<2 \mathrm{~mm}$ in diameter. Roots of plants kept in cold store were pooled from two plants per replicate and samples of $300-600 \mathrm{mg}$, consisting of one to two pieces of roots $<2 \mathrm{~mm}$ in diameter were prepared. Five replicates from each set of plants were sealed in $70-\mathrm{mL}$ test tubes with few drops of demineralized water and held at $4{ }^{\circ} \mathrm{C}$ as unfrozen control. To ensure initiation of ice crystal formation during freezing, the remaining samples were placed in $70-\mathrm{mL}$ test tubes containing $35 \mathrm{~mL}$ of frozen, demineralized water. Subsequently, the samples were incubated in a programmable freezer. The rest of the analysis was performed in the same way as the analysis of stem freezing tolerance.

Data Analysis. The effects of treatment on leaf biomass, plant-water relations, concentrations of carbohydrates and proline in leaves, and concentration of ABA in xylem sap were examined by the GLM procedure of SAS (SAS Institute, Cary, NC). Heterogeneities of variances within treatments were tested using Bartlett's test. When necessary, logarithmic transformations were performed to ensure homogeneity of variance. Differences between individual means were identified using Tukey's Studentized range (HSD) test at the 5\% significance level. A linear relationship between $\psi_{\mathrm{r}}$ and $(\mathrm{ABA})_{\mathrm{xylem}}$, determined on the same plants, was examined using Pearson's correlation coefficient, while a relation between $(\mathrm{ABA})_{\mathrm{xylem}}$ and $g_{\mathrm{s}}$ was evaluated by a logarithmic function. The parameters of the curve were derived by the nonlinear least-squares iteration procedure (PROC NLIN), and the coefficient of determination $\left(r^{2}\right)$ was calculated as $1-\mathrm{SSE} / \mathrm{CSS}$, where SSE is the residual sum of squares and CSS is the corrected total sum of squares.

Stem electrolyte leakage data were subjected to two-way analysis of variance (ANOVA) to determine the main effects of treatment and freezing temperature on REL. Tukey's HSD test was used for multiple comparisons of the effects of treatment and freezing temperature on REL. Stem REL data were arcsin square-root-transformed before analysis, but for clarity all data are presented as untransformed. A nonparametric KruskallWallis test was also used to test differences in REL of stems between treatments and freezing temperatures. This test was done to supplement the results from the two-way ANOVA, as the assumption concerning similar variance was not fulfilled. Root electrolyte leakage data were analyzed using two-way ANOVA and Tukey's HSD test to determine main effects of freezing temperature and storage (outdoor vs. cold storage) and to separate individual means. Logarithmic transformations were performed to ensure homogeneity of variance, which was tested using Bartlett's test. To estimate the temperature representing $50 \%$ injury $\left(\mathrm{LT}_{50}\right)$, data for all four (stems) or five (roots) replicates per treatment were fitted by regression analysis (PROC NLIN), to the sigmoid function $y=y_{0}+a /\{1$ $\left.+\exp \left[-\left(x-x_{0}\right) / b\right]\right\}$, where $y$ is REL with a value of $y_{0}$ at the lower asymptote, $x$ is the temperature with a value of $x_{0}$ at the inflection point representing $\mathrm{LT}_{50}$, and $a$ and $b$ are parameters. For roots of pot-grown plants kept outdoors a $\mathrm{LT}_{50}$ value could not be determined, because samples were only frozen to $-8^{\circ} \mathrm{C}$, which made it impossible to fit data to the sigmoid function. For stems, differences between $\mathrm{LT}_{50}$ estimates were taken as significant if the $95 \%$ confidence intervals did not overlap. To determine whether $\mathrm{LT}_{50}$ estimates differed between stems and roots, REL data for both stems and roots were fitted by regression analysis (PROC NLIN) to the sigmoid function $y=$ $y_{0}+a /\left\{1+\exp \left[-\left(x-\left(x_{0}+x_{0 \mathrm{rod}} \times \operatorname{rod}\right) / b\right)\right]\right\}$, where $y, y_{0}, x, a$, and $b$ are the same parameters as described above and $x_{0}$ rod is the difference between stem and root $\mathrm{LT}_{50}$ estimates. The difference in $\mathrm{LT}_{50}$ between the two tissue types was taken as significant if it differed significantly from 0 .

To sum up, plants were initially pretreated (control, continuous water deficit, and cyclic water deficit) under a long-day/ high-temperature regime in greenhouse. After 6 weeks of pretreatment, measurements and harvesting were performed. After harvesting, another set of pretreated plants was subjected to $\mathrm{SD}+\mathrm{LT}$ in climate chamber for an additional 4 weeks, while the previous treatments were continued. Finally, stem freezing tolerance was determined. During the last 4 weeks, half of the control plants stayed in the greenhouse and served as nonacclimated controls.

\section{Results}

Plant biomass. Compared with control plants, total leaf fresh weight and total leaf area were significantly reduced by $27 \%$ and $41 \%$ in cyclic and continuous water-deficit plants, respectively (Fig. 2). Water-deficit treatments also significantly affected average leaf size, which was reduced from $1.42 \mathrm{~cm}^{2}$ per leaf in control plants to an average of $1.16 \mathrm{~cm}^{2}$ per leaf and $1.32 \mathrm{~cm}^{2}$ per leaf in continuous water-deficit and cyclic waterdeficit plants, respectively (Table 1). The mean number of leaves per plant tended to decrease nonsignificantly from 400 of control plants to $\approx 300$ of both continuous and cyclic waterdeficit plants (data not shown). Cyclic water deficit decreased SLA by $14 \%$ relative to control plants, whereas SLA of continuous water-deficit plants did not differ significantly from any of the other treatment groups (Table 1).

Stomatal CONDUCtanCE and Plant-Water RElations. Both types of deficit irrigation significantly reduced $g_{\mathrm{s}}$. Compared with control plants, $g_{\mathrm{s}}$ was reduced by $\approx 55 \%$ in both continuous and cyclic water-deficit plants (Table 1). Leaf water content 


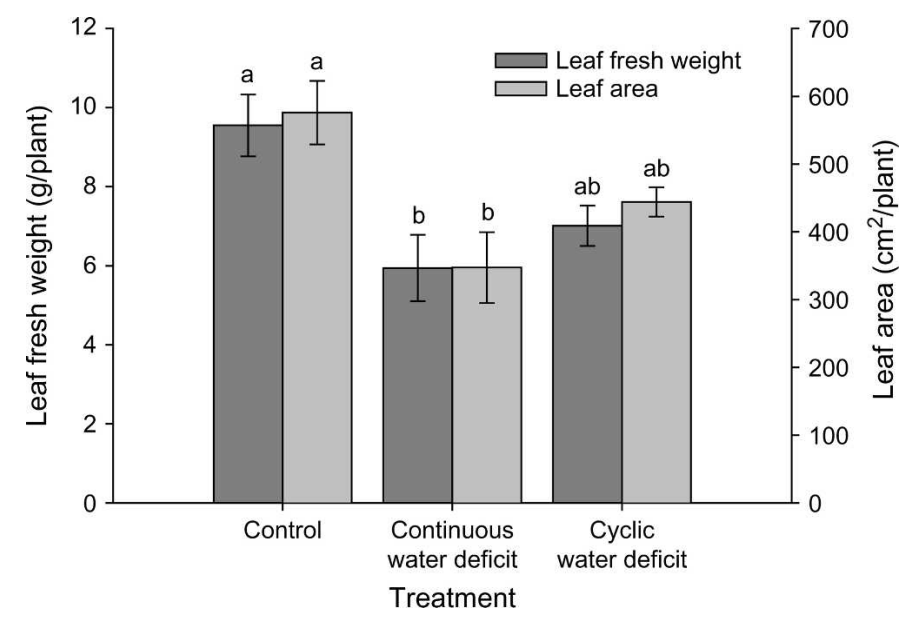

Fig. 2. Leaf area and leaf fresh weight of control, continuous water-deficit, and cyclic water-deficit Fuchsia magellanica plants after 6 weeks of treatment (mean $\pm \mathrm{SE}, n=5$ ). Different letters above bars indicate significant differences $(P<0.05)$ among treatments according to Tukey's Studentized range (HSD) test.

was only significantly reduced by cyclic water deficit by $20 \%$ relative to control and continuous water-deficit plants (Table 1). That cyclic water deficit appeared more stressful than continuous water deficit was also apparent from decreases in $\psi_{\mathrm{r}}$ and $\psi_{1}$ (Fig. 3). The root water potential did not differ significantly between control and continuous water-deficit plants but was significantly reduced, on average by $370 \%$, in cyclic waterdeficit plants. The variation in $\psi_{1}$ between plants subjected to different treatments was less pronounced than the variation in $\psi_{\mathrm{r}}$, but the tendency was the same. Neither continuous water deficit nor cyclic water deficit had any significant effects on leaf $\psi_{\mathrm{s}}$ and leaf $\psi_{\mathrm{p}}$ (data now shown). However, $\psi_{\mathrm{s}}$ tended to be lower in both stress treatments relative to control plants, whereas $\psi_{\mathrm{p}}$ tended to be higher and lower in continuous water-deficit and cyclic water-deficit plants, respectively, compared with control plants.

Carbohydrate and proline Concentrations. The leaf starch concentration was lower in cyclic water-deficit plants compared with continuous water-deficit plants, but it did not differ significantly from the concentration in well-watered plants (Table 2). Leaf hexose (glucose + fructose) concentrations tended to be higher in water-deficit than in control plants, but due to a rather large variation within treatments, differences were not statistically significant. Sucrose concentrations were generally low and very inconsistent (data not shown). The proline concentration in leaves was significantly higher, by $\approx 30 \%$, in cyclic water-deficit plants compared with the other treatments (Table 2).
XYLEM SAP (ABA). Enhanced levels of (ABA) xylem were observed in water-deficit plants. Compared with a mean

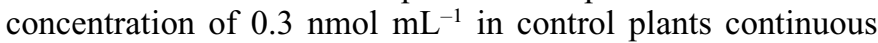
water deficit and cyclic water deficit increased (ABA) $)_{x y l e m} 2.5$ and 10 times, respectively. The relationship between $(\mathrm{ABA})_{\mathrm{xylem}}$ and $g_{\mathrm{s}}$ was inversely curvilinear and could be well described by a logarithmic function (Fig. 4, $P<0.0001$ ). There was a significant linear relationship between $\psi_{\mathrm{r}}$ and $(\mathrm{ABA})_{\mathrm{xylem}}$ across the water-deficit treatments (Fig. 5, $P<0.0001$ ).

Freezing tolerance. When assessing differences in REL of stems between treatments and freezing temperatures by two-way ANOVA or Kruskal-Wallis tests, similar results were obtained. Both types of tests showed that REL of stems was significantly affected by the freezing temperature, whereas there was no difference in freezing tolerance between treatments, indicating that neither cold-acclimating conditions nor cold-acclimating conditions combined with different types of water deficit had any significant effect on freezing tolerance in stems of $F$. magellanica. REL increased rapidly below $-4{ }^{\circ} \mathrm{C}$ and reached maximum at $-8{ }^{\circ} \mathrm{C}$. This is in accordance with both the Tukey and Mann-Whitney tests, showing that the lowest freezing test temperature inducing stem electrolyte rates, not significantly different from unfrozen samples, was $-4{ }^{\circ} \mathrm{C}$. Additionally, $\mathrm{LT}_{50}$ estimates were not different among treatments, varying between -5.2 and $-6.7^{\circ} \mathrm{C}$ (Table 3).

Root REL of cold-acclimated plants kept outdoors or in cold storage differed significantly at $4{ }^{\circ} \mathrm{C}$ but did not differ at other temperatures, indicating that plants kept outdoors had not started to deacclimate. Greater "control leakage" of roots of juvenile plants kept outdoors than from 2-year-old plants kept in cold storage could be due to their thinner structure, which may result in more injury and subsequent leakage during sample preparation. Tissue damage thresholds for roots, depicted by a rapid increase in REL, was less clear than in stems, as root REL was $<40 \%$ at all temperatures, indicating that ions were retained in the tissue, although visually roots were clearly damaged at about $-6{ }^{\circ} \mathrm{C}$ and below. However, the $\mathrm{LT}_{50}$ value for roots of cold-acclimated plants kept in cold store was significantly higher than the $\mathrm{LT}_{50}$ value for stems, indicating that $F$. magellanica roots are less freezing resistant than are stems (Table 3).

\section{Discussion}

The observed decrease in total leaf area and total leaf fresh weight in $F$. magellanica plants exposed to water deficit appeared to result mainly from a reduced average leaf size, which is a commonly observed response in woody plants subjected to drought stress (Bañon et al., 2003; Williams

Table 1. Average leaf size, specific leaf area, leaf water content, and stomatal conductance $\left(g_{\mathrm{s}}\right)$ of control, continuous water-deficit, and cyclic water-deficit Fuchsia magellanica plants after 6 weeks of treatment $(n=5){ }^{z}$

\begin{tabular}{|c|c|c|c|c|}
\hline Treatment & $\begin{array}{c}\text { Avg leaf size } \\
{\left[\text { mean } \pm \text { SE }\left(\mathrm{cm}^{2} / \text { leaf }\right)\right]}\end{array}$ & $\begin{array}{c}\text { Specific leaf area } \\
{\left[\text { mean } \pm \mathrm{SE}\left(\mathrm{cm}^{2} \cdot \mathrm{g}^{-1} \mathrm{DW}\right]\right.}\end{array}$ & $\begin{array}{c}\text { Water content, } \\
{\left[\text { mean } \pm \mathrm{SE}\left(\mathrm{g} \cdot \mathrm{g}^{-1} \mathrm{DW}\right)\right]}\end{array}$ & $\begin{array}{c}\text { Stomatal } \\
\text { conductance }\left(g_{\mathrm{s}}\right) \\
{\left[\text { mean } \pm \mathrm{SE}\left(\mathrm{mmol} \cdot \mathrm{m}^{-2} \cdot \mathrm{s}^{-1}\right)\right]}\end{array}$ \\
\hline Control & $1.42 \pm 0.05 \mathrm{a}$ & $403 \pm 7 \mathrm{a}$ & $5.69 \pm 0.04 \mathrm{a}$ & $124 \pm 9 \mathrm{a}$ \\
\hline Cyclic water deficit & $1.32 \pm 0.05 \mathrm{ab}$ & $346 \pm 30 b$ & $4.46 \pm 0.82 b$ & $53 \pm 10 b$ \\
\hline
\end{tabular}

${ }^{\mathrm{z}}$ Different letters within columns indicate significant differences $(P<0.05)$ between treatments according to Tukey's Studentized range (HSD) test. 


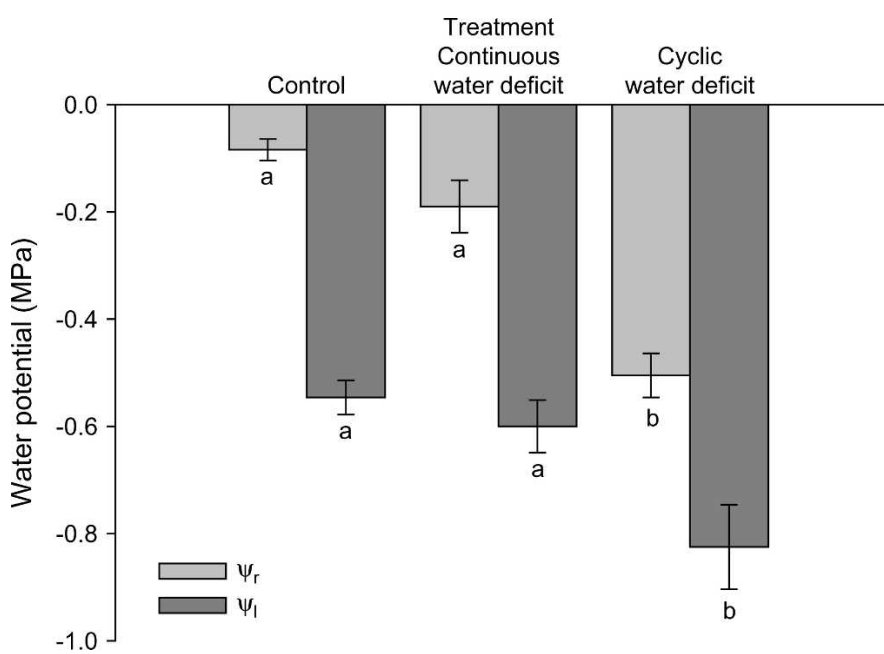

Fig. 3. Root water potential $\left(\psi_{\mathrm{r}}\right)$ and leaf water potential $\left(\psi_{1}\right)$ in well-watered and continuous or cyclic water-deficit Fuchsia magellanica plants after 6 weeks of growth [mean $\pm \mathrm{SE}, n=5$, except cyclic water deficit $(n=4)$ ] Different letters below bars indicate significant differences $(P<0.05)$ among treatments within organs according to Tukey's Studentized range (HSD) test.

et al., 1999). Reduced leaf area can be considered as a morphological adaptation to water stress to reduce transpiration and hence lower the consumption of water (Chaves et al., 2003). The average leaf number per plant tended to be lower in droughted plants, but differences were statistically insignificant, indicating that the activity of meristems was preserved during the stress period. This could be due to higher tolerance of cell division to dehydration in comparison with cell expansion, or alternatively it could be due to a better protection against dehydration of the meristem in comparison with older organs and tissues (Martinez et al., 2004). A lower SLA in droughtstressed plants than in controls is also in accordance with results obtained with other species (Galmés et al., 2005; Yin et al., 2004) and may be a result of an increased investment in structural tissues, allowing increased resistance to unfavorable environmental conditions (Chaves et al., 2003).

Besides regulating leaf area, water-deficit plants also regulated water loss by inducing stomatal closure, which can be regarded as an avoidance mechanism reducing the rate at which water deficit develops (Chaves et al., 2003). Stomatal closure has been observed not only in water-deficit plants but also in deciduous leaves of cold-acclimating woody plants ( $\mathrm{Li}$ et al., 2002, 2005).

Both continuous and cyclic water-deficit plants minimized water loss by closing stomata and reducing the leaf area, but cyclic water deficit had a much greater negative effect on the leaf water content and on $\psi_{1}$ and $\psi_{\mathrm{r}}$ compared with continuous water deficit, suggesting that $F$. magellanica is more sensitive to stress phases of cyclic water deficit than to continuous water deficit. The leaf water content has been observed to decrease in woody plant species during cold acclimation (Li et al., 2002, 2005), and cellular dehydration is believed to be beneficial in plants subjected to cold, as tissues containing a large amount of free water are highly susceptible to formation of intracellular ice (Guy, 2003). Hence, reduced leaf water content in cyclic water-deficit plants may be advantageous in terms of cold resistance. Leaf $\psi_{\mathrm{s}}$ and $\psi_{\mathrm{p}}$ tended to decrease and increase, respectively, in continuous water-deficit plants compared with control plants, indicating that continuous water-deficit $F$. magellanica plants posses a modest ability to adjust osmotically. In contrast, the reduction in $\psi_{1}$ and the nonsignificant reduction in $\psi_{\mathrm{s}}$ in cyclic water-deficit plants were probably induced by tissue dehydration since $\psi_{\mathrm{p}}$ and the leaf water content were also decreased. Lack of or limited capacity to adjust osmotically has also been observed in stems of other woody plants subjected to water deficit (Fan et al., 1994) and in leaves of drought-stressed Rhamnus alaternus L. (Banon et al., 2003). The apparent difference between continuous and cyclic water-deficit plants in ability to adjust osmotically may be ascribed to different rates of stress development, as osmotic adjustment is normally a slow process (Chaves et al., 2003). Hence, continuous water-deficit plants subjected to rather mild, prolonged drought may display modest osmotic adjustment, whereas a few days of fast droughting, as experienced by cyclic water-deficit plants, might not result in osmotic adjustment. Besides osmotic adjustment, turgor maintenance in continuous water-deficit plants may also be ascribed to adjustments in cellwall elasticity, as observed in other woody plants species (Fan et al., 1994).

The foliar hexose concentration (glucose + fructose) tended to be higher in water-deficit plants, but differences were statistically insignificant, supporting the assumption concerning lack of or limited capacity for osmotic adjustment in waterdeficit $F$. magellanica, because accumulation of sugars is generally considered to play an important role in osmotic adjustment in drought-stressed plants (Li and Li, 2005; Martinez et al., 2004). According to Kingston-Smith et al. (1998), who compared leaf sucrose, starch, and hexose contents in source leaves of 13 plant species, Fuchsia hybrida L. accumulates much less sucrose and starch than other species, which may explain why we found very low and variable leaf sucrose concentrations. In cyclic water-deficit plants, the leaf starch content was reduced, but it seemed not to be an important source of hexose accumulation, although starch turnover can affect the foliar hexose pool (Kingston-Smith et al., 1998). However, as shown in apple (Malus $\times$ domestica Borkh. 'Nagano Fuji'), water stress may primarily reduce foliar starch

Table 2. Concentrations of starch, hexose, and proline in leaves of Fuchsia magellanica after 6 weeks of growth subjected to control conditions, continuous water deficit, or cyclic water deficit $[n=5$ except starch concentration, control $(n=4)] .^{\mathrm{z}}$

\begin{tabular}{lccr}
\hline & Control & Continuous water deficit & Cyclic water deficit \\
\hline $\begin{array}{l}\text { Starch concn, dry weight yield } \\
{\left[\text { mean } \pm \text { SE }\left(\mathrm{mg} \cdot \mathrm{g}^{-1} \mathrm{DW}\right)\right]}\end{array}$ & $15.43 \pm 2.44 \mathrm{ab}$ & $18.73 \pm 1.50 \mathrm{a}$ & $8.61 \pm 1.79 \mathrm{~b}$ \\
$\begin{array}{l}\text { Hexose concn, dry weight yield } \\
{\left[\mathrm{mean} \pm \mathrm{SE}\left(\mathrm{mg} \cdot \mathrm{g}^{-1} \mathrm{DW}\right)\right]}\end{array}$ & $8.84 \pm 5.29 \mathrm{a}$ & $17.26 \pm 1.81 \mathrm{a}$ & $13.22 \pm 7.12 \mathrm{a}$ \\
$\begin{array}{l}\text { Proline concn, fresh weight yield } \\
{\left[\text { mean } \pm \mathrm{SE}\left(\mu \mathrm{mol} \cdot \mathrm{g}^{-1} \mathrm{FW}\right)\right]}\end{array}$ & $0.68 \pm 0.07 \mathrm{~b}$ & $0.56 \pm 0.02 \mathrm{~b}$ & $0.88 \pm 0.05 \mathrm{a}$ \\
\hline
\end{tabular}

${ }^{\mathrm{z}}$ Different letters within rows indicate significant differences between treatments $(P<0.05)$ according to Tukey's Studentized range (HSD) test. 


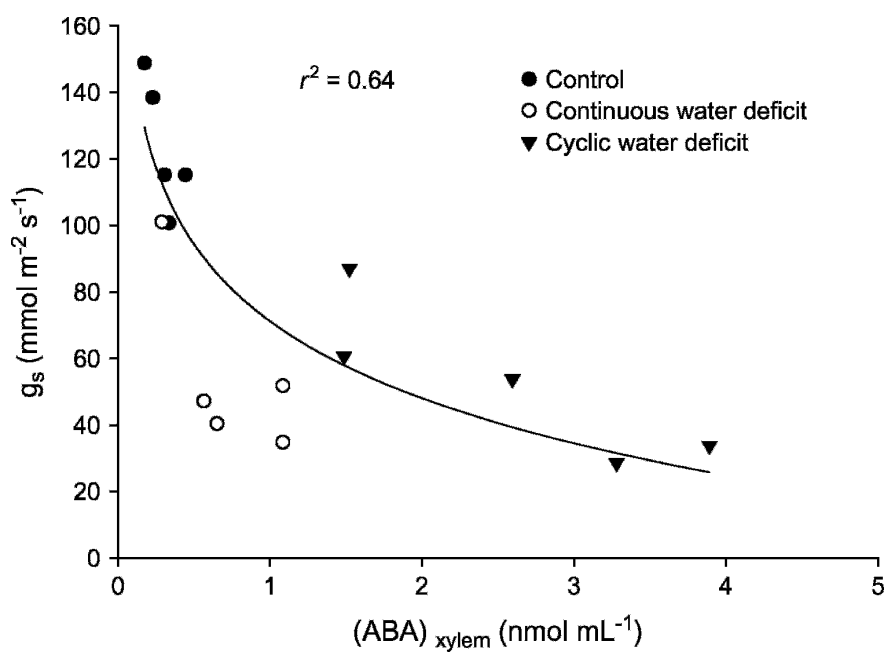

Fig. 4. Relationship between stomatal conductance $\left(g_{\mathrm{s}}\right)$ and xylem sap ABA concentrations $\left[(\mathrm{ABA})_{\mathrm{xylem}}\right]$ in control, continuous water-deficit, and cyclic water-deficit Fuchsia magellanica plants after 6 weeks of treatment $(n=15)$. $r^{2}$ significant at $P<0.0001$ when data were fitted to a logarithmic function using the nonlinear least-squares iteration procedure, where $r^{2}$ was calculated as $1-\mathrm{SSE} / \mathrm{CSS}$ where SSE is the residual sum of squares and CSS is the corrected total sum of squares.

content via decreased synthesis due to altered partitioning of newly fixed carbon ( $\mathrm{Li}$ and $\mathrm{Li}, 2005)$. Moreover, on the basis of the present results, it is not possible to rule out that $F$. magellanica might predominantly accumulate other soluble carbohydrates than hexose and sucrose during water deficit.

Constitutive proline levels in unstressed plants and proline accumulation during stress varies considerably in woody plants (Ain-Lhout et al., 2001; Martìnez et al., 2004; Matos et al., 2004). In the present experiment, the proline concentration increased significantly only in cyclic water-deficit plants, which were most severely stressed. This is in agreement with observations of Sánchez et al. (1998) and Yin et al. (2005), who reported that proline only accumulated in leaves of

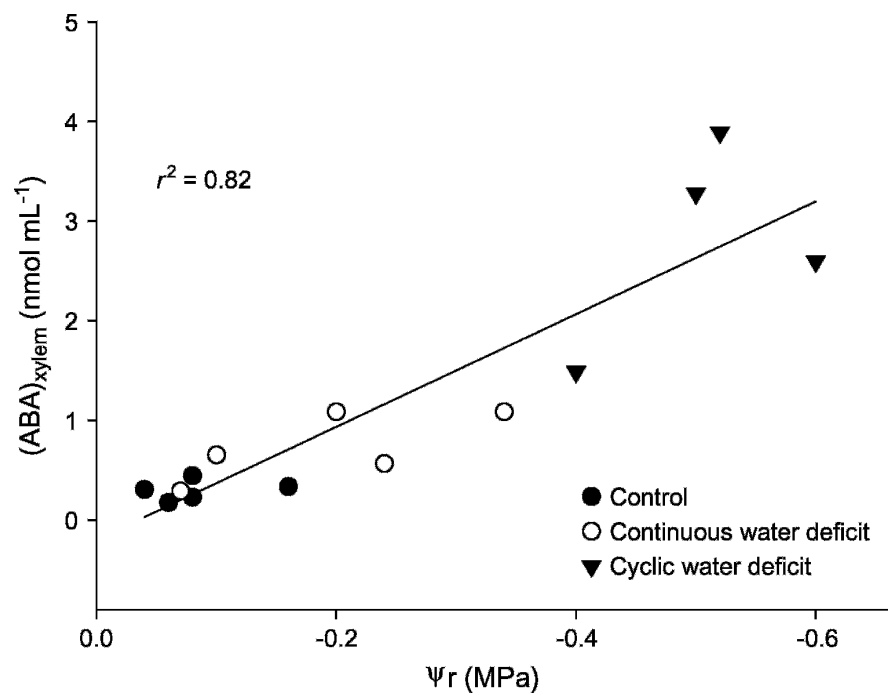

Fig. 5. Relationship between xylem sap ABA concentrations $\left[(\mathrm{ABA})_{\mathrm{xylem}}\right]$ and root water potentials $\left(\psi_{\mathrm{r}}\right)$ in control, continuous water-deficit, and cyclic water-deficit Fuchsia magellanica plants after 6 weeks of treatment $(n=14)$; $r^{2}$ significant at $P<0.001$ according to Pearson's correlation coefficient.
Table 3. Freezing tolerance assessed as $\mathrm{LT}_{50}$ values (temperatures representing $50 \%$ injury) of stems and roots of Fuchsia magellanica plants. ${ }^{\mathrm{Z}}$

\begin{tabular}{llc}
\hline Plant organ & Treatment & LT $_{50}\left[\right.$ mean \pm SE $\left.\left({ }^{\circ} \mathrm{C}\right)\right]$ \\
\hline Stems & Control & $-6.7 \pm 1.7 \mathrm{aB}$ \\
& Control + SD + LT & $-5.7 \pm 1.4 \mathrm{aB}$ \\
& Continuous water & $-5.2 \pm 0.4 \mathrm{aB}$ \\
& $\quad$ deficit + SD + LT & \\
& Cyclic water deficit & $-6.5 \pm 0.3 \mathrm{aB}$ \\
& SD + LT & \\
Roots & Kept in cold storage & $-2.9 \pm 0.4 \mathrm{~A}$ \\
\hline
\end{tabular}

${ }^{\mathrm{z}}$ Stems of plantlets were tested after 6 weeks of control, continuous water-deficit, or cyclic water-deficit pretreatments and additionally 4 weeks of treatment under short-day [SD (10 h light)] and lowtemperature [LT $\left(8^{\circ} \mathrm{C}\right.$ day $/ 4{ }^{\circ} \mathrm{C}$ night $\left.)\right]$ conditions. Roots of 2 -year-old plants were tested after cold acclimation under natural conditions and cold storage at about $-1{ }^{\circ} \mathrm{C} . \mathrm{LT}_{50}$ are shown for four (stems) or five (roots) plants tested at 10 temperatures. Different lower-case letters within the column indicate significant differences between treatments within stems, and different upper-case letters within the column indicate a significant difference between tissue types. Differences between $\mathrm{LT}_{50}$ estimates were taken as significant if the $95 \%$ confidence intervals did not overlap.

different Pisum sativum L. cultivars after considerable drops in $\psi_{1}$ and in severely drought-stressed Populus kangdingensis Wang et Tung. Considering the fairly low proline concentrations, the importance of proline as an osmolyte seems modest, but proline is confined to the cytoplasm (Aubert et al., 1999), which comprises only a small percent of the cell volume. Additionally, proline may modulate membrane permeability and ion uptake, protect protein structures, or function in redoxhomeostasis (Rai, 2002).

ABA is thought to play an important role as a signal transducer in both water-stressed and cold-acclimating plants, and the present study shows that ABA is involved in droughtstress responses in $F$. magellanica. The observed xylem sap ABA concentrations were within the range reported for other woody species (Loewenstein and Pallardy, 2002; Soar et al., 2004 ), and increasing values in water-stressed plants are in accordance with earlier reports of an increased ABA concentration induced by drought in other plant species (Davies et al., 2005). Much higher (ABA) xylem in cyclic than in continuous water-deficit plants supports the assumption of $F$. magellanica being more sensitive to cyclic water deficit than to continuous water deficit. The strong linear correlation between $(\mathrm{ABA})_{\mathrm{xylem}}$ and $\psi_{\mathrm{r}}$ indicates that $F$. magellanica is able to sense the soilwater availability and that increasing water deficiency stimulates formation of $\mathrm{ABA}$ in the roots, which is transported in the xylem sap. A similar relationship has been observed in other plants (Liu et al., 2005a, 2005b). The stomatal conductance $\left(g_{\mathrm{s}}\right)$ was closely correlated to $(\mathrm{ABA})_{\mathrm{xylem}}$, and the curvilinear correlation indicates that, as in other woody and herbaceous plants (Liu et al., 2005a; Loewenstein and Pallardy, 2002; Soar et al., 2004), root-originated xylem sap ABA might control $g_{\mathrm{s}}$ during mild water deficits, whereas at severe water deficits, the dependency of $g_{\mathrm{s}}$ on $(\mathrm{ABA})_{\mathrm{xylem}}$ is insignificant.

Cold-acclimating conditions (SD + LT) did not enhance freezing tolerance significantly in stems of $F$. magellanica compared with plants grown in the greenhouse under a longday/high-temperature regime. The apparent lack of increased freezing tolerance indicates that $F$. magellanica has not 
developed effective acclamatory responses to the cold-acclimating conditions used in this study. According to Sakai and Larcher (1987), freezing temperatures down to about $-5^{\circ} \mathrm{C}$ are common in freezing-sensitive species due to accumulated solutes inside cells, which might explain the minor capacity of $F$. magellanica to withstand freezing temperatures. Alternatively, $F$. magellanica's cold-acclimation potential may be $<2{ }^{\circ} \mathrm{C}$, which was the freezing temperature interval used in the present study. In the tropical woody plant species Nothofagus nitida (Phil.) Krasser exhibiting freezing avoidance, a very modest increase in leaf freezing resistance $\left(\approx 2{ }^{\circ} \mathrm{C}\right)$ was observed during cold acclimation (Reyes-Díaz et al., 2005). Hence, the acclimation capacity of $F$. magellanica may be marginal and therefore not apparent in the present study. Otherwise $F$. magellanica may require lower temperatures to initiate cold acclimation, as taxa acclimate differentially within a given temperature range (Weiser, 1970).

Water deficit has been shown to enhance freezing tolerance in some woody plant species in the Northern Hemisphere, although the increase may be small (Anisko and Lindstrom, 1996; Li et al., 2002; Rinne et al., 1998). However, our results showed that water deficit applied before and during coldacclimating conditions did not influence freezing tolerance of F. magellanica stems. Because accumulation of solutes (e.g., soluble carbohydrates and proline) is essential in plants displaying freezing avoidance (Rada et al., 2001; Reyes-Díaz et al., 2005), the reason why water deficit did not enhance freezing resistance of $F$. magellanica may be ascribed to lack of or very modest accumulation of soluble carbohydrates during drought stress. However, if $F$. magellanica has not developed acclamatory responses to freezing, it may be unfeasible to improve freezing resistance via accumulation of soluble sugars. In that case, it is also unlikely that $\mathrm{ABA}$ production triggered by water deficit influences freezing tolerance. Although cyclic water deficit induced leaf dehydration, it did not improve freezing tolerance of stems. Hence, stems may not have been dehydrated or tissue dehydration alone is insufficient to increase freezing tolerance. Freezing tolerance of $F$. magellanica roots was lower than stem freezing tolerance. It is commonly observed in woody plants that roots seldom attain the same degree of freezing resistance as aboveground parts (Ryyppö et al., 1998; Sakai and Larcher, 1987; Stattin and Lindström, 1999), demonstrating that the frequent ability of $F$. magellanica to produce new shoots after killing of stems presumably is due to the lower impact of frost action in the soil.

In conclusion, the present findings indicate that $F$. magellanica, under both continuous and cyclic water deficit, postpones dehydration by modulating leaf area and closing stomata, whereas only continuous water-deficit plants develop modest leaf osmotic adjustment. Water deficiency stimulates formation of $\mathrm{ABA}$ in the roots, which, at mild water deficit, probably regulates stomatal closure. F. magellanica stems and roots are most likely freezing sensitive, and due to $F$. magellanica's lack of acclamatory mechanisms to cold-acclimating conditions used in this study or since drought stress is not associated with alterations of plant-water relations beneficial in terms of freezing resistance, water deficit applied before and during cold acclimation does not improve freezing tolerance. In terms of management practice, it is therefore unlikely that successful over-wintering of $F$. magellanica outdoors in Denmark and in similar climatic areas can be obtained as a result of drought treatments before cold stress.

\section{Literature Cited}

Aasamaa, K., A. Sõber, W. Hartung, and U. Niinemets. 2002. Rate of stomatal opening, shoot hydraulic conductance and photosynthetic characteristics in relation to leaf abscisic acid concentration in six temperate deciduous trees. Tree Physiol. 22:267-276.

Ain-Lhout, F., M. Zunzunegui, M.C.D. Barradas, R. Tirado, A. Clavijo, and F.G. Nova. 2001. Comparison of proline accumulation in two Mediterranean shrubs subjected to natural and experimental water deficit. Plant Soil 230:175-183.

Amundson, R.G., R.J. Kohut, J.A. Laurence, S. Fellows, and L.J. Colavito. 1993. Moderate water stress alters carbohydrate content and cold tolerance of red spruce foliage. Environ. Expt. Bot. 33: 383-390.

Anisko, T. and O.M. Lindstrom. 1996. Cold hardiness and water relations parameters in Rhododendron cv. Catawbiense Boursault subjected to drought episodes. Physiol. Plant. 98:147-155.

Arora, R., M.E. Wisniewski, and R. Scorza. 1992. Cold acclimation in genetically related (sibling) deciduous and evergreen peach (Prunus persica (L.) Batsch). Plant Physiol. 99:1562-1568.

Asch, F., M.N. Andersen, C.R. Jensen, and V.O. Mogensen. 2001. Ovary abscisic acid concentration does not induce kernel abortion in field-grown maize subjected to drought. Eur. J. Agron. 15:119-129.

Aubert, S., F. Hennion, A. Bouchereau, E. Gout, R. Bligny, and A.-J. Dorne. 1999. Subcellular compartmentation of proline in the leaves of the subantarctic Kerguelen cabbage Pringlea antiscorbutica R.Br. in vivo C-13-NMR study. Plant Cell Environ. 22:255-259.

Bañon, S., J. Ochoa, J.A. Franco, M.J. Sánchez-Blanco, and J.J. Alarcon. 2003. Influence of water deficit and low air humidity in the nursery on survival of Rhamnus alternus seedlings following planting. J. Hort. Sci. Biotechnol. 78:518-522.

Berry, P.E., W.J. Hahn, K.J. Sytsma, J.C. Hall, and A. Mast. 2004. Phylogenetic relationships and biogeography of Fuchsia (Onagraceae) based on noncoding nuclear and chloroplast DNA data. Amer. J. Bot. 91:601-614.

Chaves, M.M., J.P. Maroco, and J.S. Pereira. 2003. Understanding plant responses to drought-from genes to the whole plant. Funct. Plant Biol. 30:239-264.

Davies, W.J., G. Kudoyarova, and W. Hartung. 2005. Long-distance ABA signalling and its relation to other signalling pathways in the detection of soil drying and the mediation of the plant's response to drought. J. Plant Growth Regulat. 24:285-295.

Fan, S., T.J. Blake, and E. Blumwald. 1994. The relative contribution of elastic and osmotic adjustments to turgor maintenance of woody species. Physiol. Plant. 90:408-413.

Galmés, J., J. Cifre, H. Medrano, and J. Flexas. 2005. Modulation of relative growth rate and its components by water stress in Mediterranean species with different growth forms. Oecologia 145:21-31.

Guak, B. and L.H. Fuchigami. 2001. Effects of applied ABA on growth cessation, bud dormancy, cold acclimation, leaf senescence and $\mathrm{N}$ mobilization in apple nursery plants. J. Hort. Sci. Biotechnol. 76:459-464.

Gusta, L.V., M. Wisniewski, N.T. Nesbitt, and L.M. Gusta. 2004. The effect of water, sugars, and proteins on the pattern of ice nucleation and propagation in acclimated and nonacclimated canola leaves. Plant Physiol. 135:1642-1653.

Gusta, L.V., R. Trischuk, and C.J. Weiser. 2005. Plant cold acclimation: the role of abscisic acid. J. Plant Growth Regulat. 24:308-318. Guy, C.L. 2003. Freezing tolerance of plants: current understanding and selected emerging concepts. Can. J. Bot. 81:1216-1223.

Kingston-Smith, A., N. Galtier, C.J. Pollock, and C.H. Foyer. 1998. Soluble acid invertase activity in leaves is independent of species differences in leaf carbohydrates, diurnal sugar profiles and paths of phloem loading. New Phytol. 139:283-292.

Lennartsson, M. and E. Ögren. 2002. Causes of variation in cold hardiness among fast-growing willows (Salix spp.) with particular reference to their inherent rates of cold hardening. Plant Cell Environ. 25:1279-1288. 
Li, C., T. Puhakainen, A. Welling, A. Viherä-Aarnio, A. Ernstsen, O. Junttila, P. Heino, and E.T. Palva. 2002. Cold acclimation in silver birch (Betula pendula). Development of freezing tolerance in different tissues and climatic ecotypes. Physiol. Plant. 116:478-488. Li, C., O. Junttila, and E.T. Palva. 2004. Environmental regulation and physiological basis of freezing tolerance in woody plants. Acta Physiol. Plant. 26(2):213-222.

Li, C., N. Wu, and S. Liu. 2005. Development of freezing tolerance in different altitudinal ecotypes of Salix paraplesia. Biol. Plant. 49: 65-71.

Li, T.H. and S.H. Li. 2005. Leaf responses of micropropagated apple plants to water stress: non-structural carbohydrate composition and regulatory role of metabolic enzymes. Tree Physiol. 25:495-504.

Liu, F., C.R. Jensen, and M.N. Andersen. 2004. Drought stress effect on carbohydrate concentration in soybean leaves and pods during early reproductive development: its implication in altering pod set. Field Crops Res. 86:1-13.

Liu, F., C.R. Jensen, A. Shahanzari, M.N. Andersen, and S.E. Jacobsen. 2005a. ABA regulated stomatal control and photosynthetic water use efficiency of potato (Solanum tuberosum L.) during progressive soil drying. Plant Sci. 168:831-836.

Liu, F., M.N. Andersen, S.E. Jacobsen, and C.R. Jensen. 2005 b. Stomatal control and water use efficiency of soybean (Glycine max L. Merr.) during progressive soil drying. Environ. Exp. Bot. 54:33-40. Loewenstein, N.J. and S.G. Pallardy. 2002. Influence of a drying cycle on post-drought xylem sap abscisic acid and stomatal responses in young temperature deciduous angiosperms. New Phytol. 156:351361.

Martìnez, J.-P., S. Lutts, A. Schanck, M. Bajji, and J.-M. Kinet. 2004. Is osmotic adjustment required for water stress resistance in the Mediterranean shrub Atriplex halimus L.? J. Plant Physiol. 161: 1041-1051.

Matos, M.C., E. Rebelo, J. Lauriano, J. Semedo, N. Marques, P.S. Campos, A. Matos, and J. Vieira-Da-Silva. 2004. $\mathrm{CO}_{2}$ assimilation and water relations of almond tree (Prunus amygdalus Batsch) cultivars grown under field conditions. Photosynthetica 42:473-476.

Munns, R. 1988. Why measure osmotic adjustment? Aust. J. Plant Physiol. 15:717-726.

Rada, F., C. García-Núnez, C. Boero, M. Gallardo, M. Hilal, J. González, F. Prado, M. Liberman-Cruz, and A. Azócar. 2001. Low-temperature resistance in Polylepis tarapacana, a tree growing at the highest altitudes in the world. Plant Cell Environ. 24:377-381.

Rai, V.K. 2002. Role of amino acids in plant responses to stresses. Biol. Plant. 45:481-487.

Reyes-Díaz, M., M. Alberdi, F. Piper, L.A. Bravo, and L.J. Corcuera. 2005. Low temperature response of Nothofagus dombeyi and Nothofagus nitida, two evergreen species from south central Chile. Tree Physiol. 25:1389-1398.

Rinne, P., A. Welling, and P. Kaikuranta. 1998. Onset of freezing tolerance in birch (Betula pubescens Ehrh.) involves LEA proteins and osmoregulation and is impaired in an ABA-deficient genotype. Plant Cell Environ. 21:601-611.

Ryyppö, A., T. Repo, and E. Vapaavuori. 1998. Development of freezing tolerance in roots and shoots of Scots pine seedlings at nonfreezing temperatures. Can. J. For. Res. 28:557-565.
Sakai, A. and W. Larcher. 1987. Frost survival of plants. Responses and adaptation to freezing stress. Springer-Verlag, Heidelberg, Germany.

Sánchez, F.J., M. Manzanares, E.F. de Andres, J.L. Tenorio, and L. Ayerbe. 1998. Turgor maintenance, osmotic adjustment and soluble sugar and proline accumulation in 49 pea cultivars in response to water stress. Field Crops Res. 59:225-235.

Shinozaki, K. and K. Yamaguchi-Shinozaki. 1996. Molecular responses to drought and cold stress. Curr. Opin. Biotechnol. 7:161-167.

Skriver, K. and J. Mundy. 1990. Gene expression in response to abscisic acid and osmotic stress. Plant Cell 2:503-512.

Soar, C.J., J. Speirs, S.M. Maffei, and B.R. Loveys. 2004. Gradients in stomatal conductance, xylem sap ABA and bulk leaf ABA along canes of Vitis vinifera cv. Shiraz: molecular and physiological studies investigating their source. Funct. Plant Biol. 31:659669.

Stattin, E. and A. Lindström. 1999. Influence of soil temperature on root freezing tolerance of scots pine (Pinus sylvestris L.) seedlings. Plant Soil 217:173-181.

Tamayo, P.R. and N.R. Bonjoch. 2001. Free proline quantification, p. 365-382. In: M.J.R. Roger (ed.). Handbook of plant ecophysiology techniques. Kluwer Academic Publishers, Dordrecht, The Netherlands.

Villalba, R., A. Lara, J.A. Boninsegna, M. Masiokas, S. Delgado, J.C. Aravena, F.A. Roig, A. Schmelter, A. Wolodarsky, and A. Ripalta. 2003. Large-scale temperature changes across the southern Andes: 20 th century variations in the context of the past 400 years. Clim. Change 59:177-232.

Wardle, P., C. Ezcurra, C. Ramírez, and S. Wagstaff. 2001. Comparison of the flora and the vegetation of the Southern Andes and New Zealand. N.Z. J. Bot. 39:69-108.

Weiser, C.J. 1970. Cold resistance and injury in woody plants. Science 169(3952):1269-1278.

Welling, A., P. Kaikuranta, and P. Rinne. 1997. Photoperiodic induction of dormancy and freezing tolerance in Betula pubescens. Involvement of ABA and dehydrins. Physiol. Plant. 100:119-125.

Welling, A., T. Moritz, E.T. Palva, and O. Junttila. 2002. Independent activation of cold acclimation by low temperature and short photoperiod in hybrid aspen. Plant Physiol. 129:1633-1641.

Williams, M.H., E. Rosenqvist, and M. Buchhave. 1999. Response of potted miniature roses $($ Rosa $\times$ hybrida $)$ to reduced water availability during production. J. Hort. Sci. Biotechnol. 74:301-308.

Wisniewski, M., C. Bassett, and L.V. Gusta. 2003. An overview of cold hardiness in woody plants: seeing the forest through the trees. HortScience 38:952-959.

Xin, Z. and J. Browse. 2000. Cold comfort farm: the acclimation of plants to freezing temperatures. Plant Cell Environ. 23:893-902.

Yin, C., B. Duan, X. Wang, and C. Li. 2004. Morphological and physiological responses of two contrasting poplar species to drought stress and exogenous abscisic acid application. Plant Sci. 167:10911097.

Yin, C., Y. Peng, R. Zang, Y. Zhu, and C. Li. 2005. Adaptive responses of Populus kangdingensis to drought stress. Physiol. Plant. 123: 445-451. 